\title{
Macrocyclic Formals. V. Cationic Polymerization of 1,3,6,9,12-Pentaoxacyclotetradecane
}

\author{
Yuhsuke Kawakami, Jyoji Suzuki, and Yuya Yamashita \\ Department of Synthetic Chemistry, Faculty of Engineering, \\ Nagoya University, Nagoya 464, Japan.
}

(Received April 26, 1977)

\begin{abstract}
Cationic polymerization of 1,3,6,9,12-pentaoxacyclotetradecane (14-CF5) with boron trifluoride ether complex as an initiator was studied. The polymerization proceeded in two stages. There seems to be two different active species involved in this two-stage polymerization. In order to obtain a general idea of the nature of the active species for each stage, the effect of the nature of the solvents and the copolymerization with styrene were studied.
\end{abstract}

KEY WORDS Macrocyclic Compound / Cationic Polymerization /

Gel Chromatography / Cyclic Oligomer / Active Species / Cyclic

Formal / Copolymerization / Styrene /

There has been considerable discussion in regard to the reaction mechanism of cationic polymerization of 1,3-dioxolane. Four kinds of reaction mechanisms have been proposed: the carboxonium ion, ${ }^{1}$ the tertiary oxonium ion, ${ }^{2}$ the secondary oxonium ion, ${ }^{3}$ and the polymer complexed tertiary oxonium ion ${ }^{4}$ mechanisms. However, the facts presented are not always consistent with one another. These four reaction mechanisms are based fundamentally on the idea that only one kind of active species is operating in the polymerization process. Black and Worsfold ${ }^{5}$ proposed that two different mechanisms are operating at the same time in the polymerization of 1,3-dioxolane, giving low molecular weight material and high polymer. We also reported the two-stage polymerization of 1,3-dioxa-cycloalkanes in which cyclic oligomers and high polymers are formed..$^{6-9}$

We have proposed the carboxonium ion ${ }^{1 a}$ and tertiary oxonium ion mechanisms which we favor over other types. ${ }^{1 a, 10-12}$ Recently, Okada and Sumitomo reported that the linear carboxonium ion can be detected in NMR spectrum. ${ }^{13}$

It is well recognized that cyclic oligomers are often formed during the polymerization of cyclic compounds, ${ }^{14-17}$ and the recent development in high-speed liquid chromatography has made it possible to carry out the quantitative analysis on the oligomers. Information on the reaction mechanism can be obtained by studying the structure and quantity of the products.

We synthesized macrocyclic formals which have ether oxygen as well as acetal oxygen, in that we have been interested in their polymerization behavior and complexing ability. In the course of our study, it was found that a macrocyclic formal, such as 1,3,6,9-tetraoxacycloundecane (11-CF-4), was polymerized in two stages, forming cyclic oligomers in the first stage and mainly high polymers in the second stage $^{6-9} \quad \mathrm{~A}$ fourteen-membered cyclic formal 14-CF-5 was found capable of complexing with alkali metal picrate and potassium permanganate. ${ }^{18}$ In this report the polymerization behavior of 14-CF-5 is discussed.

\section{EXPERIMENTAL}

\section{Synthesis of Macrocyclic Formals}

Prepolymers having molecular weight ranging well up in the thousands were obtained by refluxing paraformaldehyde with poly(ethylene glycol) in benzene, with the continuous removal of the water formed using $p$-toluenesulfonic acid as a catalyst. ${ }^{19,20}$ After removal of the solvent, 
$\mathrm{HO}\left(\mathrm{CH}_{2} \mathrm{CH}_{2} \mathrm{O}\right)_{m} \mathrm{H}+\mathrm{HCHO} \stackrel{\mathrm{H}^{+}}{\longrightarrow}\left\{\left(\mathrm{CH}_{2} \mathrm{CH}_{2} \mathrm{O}\right)_{m} \mathrm{CH}_{2}-\mathrm{O}\right\}_{n}$
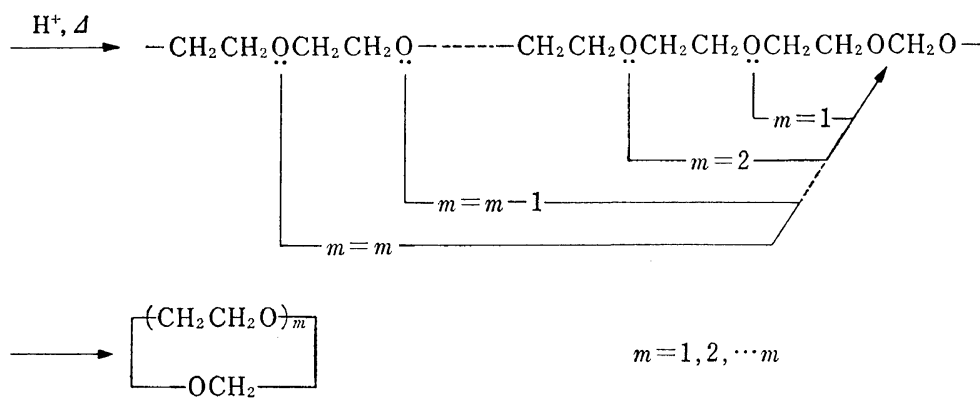

$m=1,2, \cdots m$

\section{[I]}

Diagram 1. Formation of smaller ring-size formals through random back-biting

Table I. Yield of macrocyclic formal (I)

\begin{tabular}{|c|c|c|c|c|c|c|c|}
\hline \multirow{2}{*}{ Formal } & \multirow{2}{*}{$m^{\mathrm{a}}$} & \multicolumn{6}{|c|}{ Yield, $\%$} \\
\hline & & $m=m$ & $m=m-1$ & $m=m-2$ & $m=m-3$ & $m=m-4$ & $m=m-5$ \\
\hline 1,3-Dioxolane & 1 & 98 & - & - & - & - & - \\
\hline 1,3,6-Trioxocane & 2 & 90 & 8 & - & - & - & - \\
\hline $11-\mathrm{CF}-4^{\mathrm{b}}$ & 3 & 45 & 9 & 3 & - & - & - \\
\hline $14-C F-5^{b}$ & 4 & 40 & 7 & 1.5 & 0.5 & - & - \\
\hline $17-\mathrm{CF}-6^{\mathrm{b}}$ & 5 & 39 & 5 & 3 & 1 & 0.5 & - \\
\hline $20-$ CF- $7^{b, c}$ & 6 & - & - & - & - & - & - \\
\hline 1,3-Dioxa-cyclooctaned & - & 95 & - & - & - & - & - \\
\hline
\end{tabular}

a $m$ denotes the number of ethyleneoxy repeating unit in Diagram 1.

b Abbreviations for cyclic formals. For example 11-CF-4 is the abbreviation for 11-membered cyclic formals which have 4 oxygens in the ring of [I].

c Could not be synthesized. 18

d A small amount of cyclic dimer is formed.

the residual prepolymer containing the catalyst was decomposed under vacuum at $250-300^{\circ} \mathrm{C}^{20}$ Small amounts of smaller macrocyclic formals were in the decomposition distillate, as shown in Diagram 1.

The desired formals were easily separated by fractional distillation through a $30-\mathrm{cm}$ Vigreaux column. The yields of macrocyclic formals, starting from several kinds of glycols, are given in Table I.

1,3,6,9-Tetraoxacycloundecane: bp $62^{\circ} \mathrm{C}(0.6$ $\mathrm{mm}) ; \mathrm{mp} 23.0^{\circ} \mathrm{C} ; n_{\mathrm{D}}^{30} 1.4536$. Anal. Found: $\mathrm{C}$, 51.85; $\mathrm{H}, 8.77$. Calcd for $\mathrm{C}_{7} \mathrm{H}_{14} \mathrm{O}_{4}: \mathrm{C}, 51.82$; $\mathrm{H}$, 8.71. $\mathrm{NMR}\left(\mathrm{CDCl}_{3}\right) \delta 3.50(\mathrm{~s}, 4 \mathrm{H}), 3.67(\mathrm{~s}$, $8 \mathrm{H}), 4.58(\mathrm{~s}, \quad 2 \mathrm{H}) . \quad 1,3,6,9,12$-pentaoxacyclotetradecane: bp $90^{\circ} \mathrm{C}(0.2 \mathrm{~mm}) ; \mathrm{mp} 20.5-21.5^{\circ} \mathrm{C}$. Anal. Found: C, 52.51; H, 8.61. Calcd for
$\mathrm{C}_{9} \mathrm{H}_{18} \mathrm{O}_{5}: \mathrm{C}, 52.39 ; \mathrm{H}, 8.80 . \operatorname{NMR}\left(\mathrm{CDCl}_{3}\right) \delta 3.70$ $(\mathrm{s}, 8 \mathrm{H}), 3.80(\mathrm{~s}, 8 \mathrm{H}), 4.77(\mathrm{~s}, 2 \mathrm{H}) . \quad 1,3,6,9,12,15-$ hexaoxa-cycloheptadecane: bp $135^{\circ} \mathrm{C}(0.2 \mathrm{~mm})$. Anal. Found: C, 52.94; H, 8.86. Calcd for $\mathrm{C}_{11} \mathrm{H}_{22} \mathrm{O}_{6}: \mathrm{C}, 52.76 ; \mathrm{H}$, 8.86. $\mathrm{NMR}\left(\mathrm{CDCl}_{3}\right) \delta$ $3.68(\mathrm{~s}, 8 \mathrm{H}), 3.75(\mathrm{~s}, 12 \mathrm{H}), 4.73(\mathrm{~s}, 2 \mathrm{H})$.

Dichloromethane was washed with sulfuric acid and distilled over phosphorus pentoxide after being refluxed for $5 \mathrm{hr}$. The boron trifluoride ether complex was distilled under nitrogen atmosphere. The reactions, under nitrogen atmosphere, were carried out in a one-necked flask fitted with a serum capped three-way cock. The reaction was started by adding boron trifluoride ether complex to the dichloromethane solution of the monomer. An adequate amount of reaction mixture was removed from the 
reaction system by a syringe by way of the serum cap and analysed by gas chromatography and gel chromatography after bringing the reaction to a stop with excess triethylamine. A Hitachi model K53 was used for the gas chromatograph, connected with a 1-m Silicone GE SE30 column. The time-conversion relationship was determined by measuring the monomer consumption on gas chromatograph, using $n$-hexadecane as the internal standard. For the liquid chromatograph, a Toyo Soda model HLC 802-UR connected with $2 \mathrm{~m}$ of TSK GEL G2000 H8 (nominal porosity $2.5 \times 10^{2} \AA$, TP/F 8000) (Toyo Soda) was used. The solvent for chromatography was chloroform. The flow rate was $1 \mathrm{ml} / \mathrm{min}$ at $35^{\circ} \mathrm{C}$. Three counts corresponded approximately to $2 \mathrm{ml}$ of elution, the higher count-numbers indicating the lower molecular weight. For the gel-chromatography detectors, the differential refractometer and UV spectrometer at $254 \mathrm{~nm}$ were used.

\section{RESULTS AND DISCUSSION}

Figure 1 shows the time-conversion relationship determined from the consumption of monomer. The reaction proceeded relatively slow until the conversion reached about $20 \%$ but much faster thereafter and then reached equilibrium. The first-order plot with the consumption of monomer according to the scheme of conventional equilibrium polymerization is shown in Figure 2. The two different slopes for the reaction time suggested that the reaction proceeds in two stages. Change in the gel chromatogram with the consumption of monomer is shown in Figure 3. Corresponding to the results in Figures 1 and 2, only oligomers are formed at low conversion and mainly high polymers are formed at high conversion. It is clear that there are two stages in the polymerization. The first stage is formation of oligomers and the second, the formation of polymers mainly.

The molecular weight of the polymer formed in the second stage is about $2 \times 10^{4}$ and does not seem to change with the conversion of the monomer. Two of the oligomers formed in the first stage (A and B in Figure 3) were isolated by preparative liquid chromatography and iden- tified as cyclic dimer and trimer, respectively.

Cyclic dimer of 14-CF-5. Anal. Found: C, 52.51; $\mathrm{H}, 8.92$. Calcd for $\left(\mathrm{C}_{9} \mathrm{H}_{18} \mathrm{O}_{5}\right)_{2}: \mathrm{C}, 52.39$; $\mathrm{H}, 8.80$. $\mathrm{mp} 40.5-41.0^{\circ} \mathrm{C}$; no absorption in $\mathrm{OH}$ region in IR; $\mathrm{NMR}\left(\mathrm{CDCl}_{3}\right) \delta 3.69,3.74$ (two s, 32H) 4.79 (s, 4H); MW (VPO) 420 (412). Cyclic trimer of 14-CF-5. Anal. Found: C, 52.48; $\mathrm{H}$, 8.94. Calcd for $\left(\mathrm{C}_{9} \mathrm{H}_{18} \mathrm{O}_{5}\right)_{3}: \mathrm{C}, 52.39 ; \mathrm{H}, 8.80$. Liquid; no absorption in $\mathrm{OH}$ region in IR; $\operatorname{NMR}\left(\mathrm{CDCl}_{3}\right) \delta 3.68,3.70$ (two s, 48H) 4.77 (s, 6H); MW (VPO) 625 (618). The higher molecular weight oligomers were assumed to

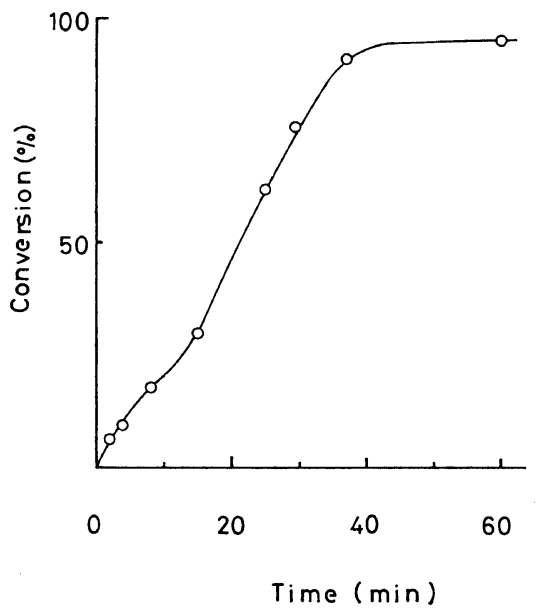

Figure 1. Time-conversion relationship in the polymerization of $14 \mathrm{CF}-5$ by $\mathrm{BF}_{3} \mathrm{OEt}_{2}$ in dichloromethane at $0^{\circ} \mathrm{C}:[14-\mathrm{CF}-5] 0,5.5 \times 10^{-1} \mathrm{M}$; $\left[\mathrm{BF}_{3} \mathrm{OEt}_{2}\right], 5.1 \times 10^{-3} \mathrm{M}$.

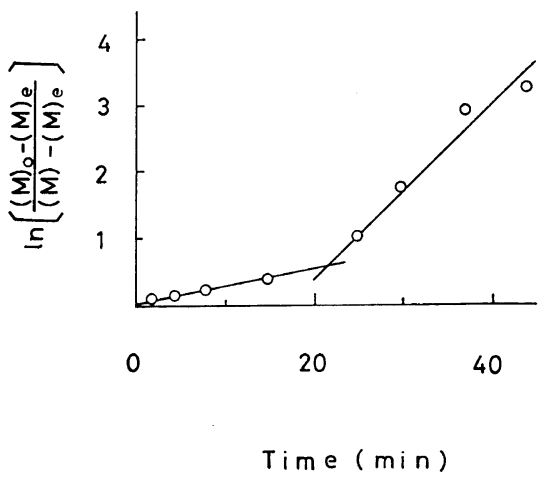

Figure 2. First-order plot of the monomer consumption in the polymerization at $0^{\circ} \mathrm{C}$ in dichloromethane: [14-CF-5], $5.5 \times 10^{-1} M$; $\left[\mathrm{BF}_{3} \mathrm{OEt}_{2}\right]$, $5.1 \times 10^{-3} M$. 


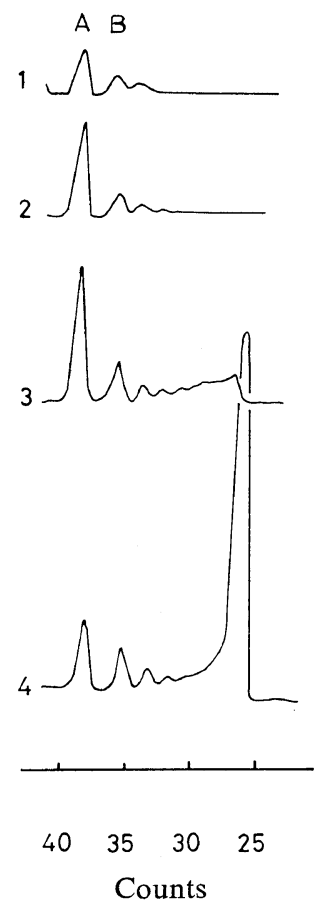

Figure 3. Change in gel chromatogram in the course of the polymerization at $0^{\circ} \mathrm{C}$ in dichloromethane: [14-CF-5], $5.5 \times 10^{-1} \mathrm{M} ;\left[\mathrm{BF}_{3} \mathrm{OEt}_{2}\right]$, $5.1 \times 10^{-3} M$; (1) $4 \mathrm{~min}, 9.5-\%$ conv; (2) $8 \mathrm{~min}$, $18.0-\%$ conv; (3) $15 \mathrm{~min}, 30.0-\%$ conv; (4) $30 \mathrm{~min}$, 75.3-\% conv; A, cyclic dimer of 14-CF-5; B, cyclic trimer of 14-CF-5.

be cyclic. Since the polymer was very hygroscopic, it was difficult to determine if the polymers have terminal groups or not.

The concentration of cyclic oligomers in the system seems to reach an equilibrium shortly after the first stage, and does not change during the polymerization. The equilibrium concentrations of cyclic dimer and trimer were $2.3 \times$ $10^{-2} \mathrm{~mol} / l$ and $0.9 \times 10^{-2} \mathrm{~mol} / l$, respectively and the equilibrium concentration of higher cyclic oligomers decreased with an increase in ring size. $^{21}$ The equilibrium concentration of monomer was $2.1 \times 10^{-2} \mathrm{~mol} / l$. The thermodynamic parameters will be discussed later. ${ }^{22}$

In order to clarify the nature of the propagating species in the first and second stages, the effects of solvents and copolymerization with styrene were examined. The effects of solvents on reaction rate are shown in Figure 4. In

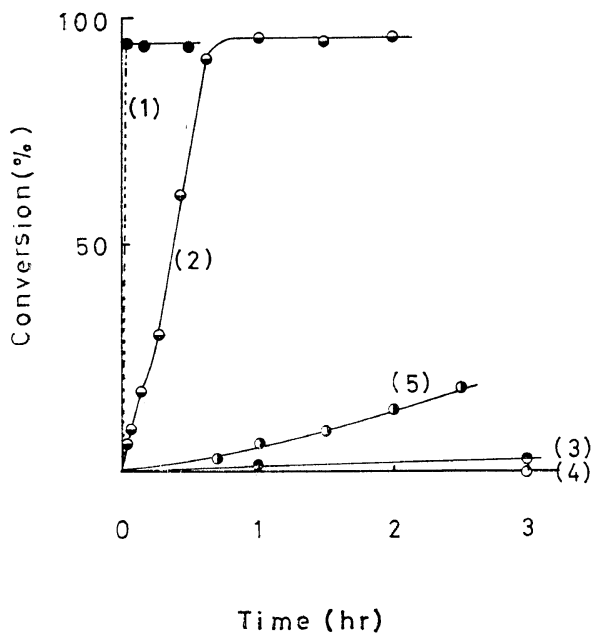

Figure 4. Effects of various solvents on the timeconversion relationship in the polymerization of $14-\mathrm{CF}-5$ at $0^{\circ} \mathrm{C}:[14-\mathrm{CF}-5]_{0}, 5.5 \times 10^{-1} \mathrm{M}$; [BF $\left.\mathrm{BEt}_{2}\right]$, $5.1 \times 10^{-3} M$; (1) $\bigcirc$, nitromethane; (2) $\ominus$, dichloromethane; (3) $\Theta, 1,3$-dioxane (at $10^{\circ} \mathrm{C}$ ); (4) $\bigcirc$, 1,2-dimethoxyethane; (5) $\mathrm{O}$, dichloromethane with $2.5 \times 10^{-3} M\left(\frac{1}{2}\left[\mathrm{BF}_{3} \mathrm{OEt}_{2}\right]\right)$ of methanol.

nitromethane, the reaction is almost instantaneous and the product distribution is almost the same as compared to that in dichloromethane, but contrary to this, the reactions in ether solvents are quite slow. In dioxane the first oligomer formation stage is very slow as is shown in Figure 4 but the second stage is relatively fast although not shown in the figure. The addition of methanol hampered the first oligomer-formation stage as is shown in Figure 4 , but had no effect on the second polymerformation stage once it was started. This is not shown in the figure.

These solvent effects favor the oxonium ionic character of the active species in the first oligomer-formation stage. The product distribution of the high-conversion system was quite similar for all the solvents examined.

It is known that styrene copolymerizes with 1,3-dioxolane and this is due perhaps to the fact that the propagating species has carbocationic nature. ${ }^{1 a, 23}$ Although the reaction rate seems to be affected very much by a small amount of contaminated water, the two-stage character of the polymerization is not altered. 
Macrocyclic Formals. V.

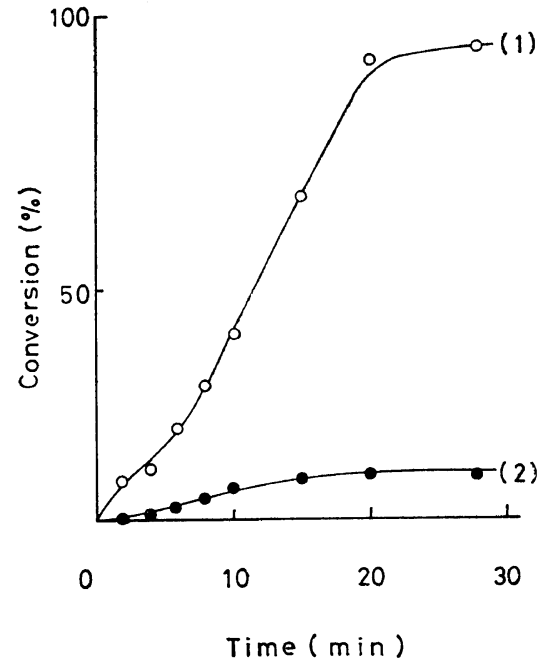

Figure 5. Time-conversion relationship in the copolymerization of $14-\mathrm{CF}-5$ with styrene, at $0^{\circ} \mathrm{C}$ in dichloromethane: [14-CF-5], $5.0 \times 10^{-1} M$; [St], $1.0 \mathrm{M} ; \quad\left[\mathrm{BF}_{3} \mathrm{OEt}_{2}\right], 5.0 \times 10^{-3} M$; (1) $\bigcirc, 14-\mathrm{CF}-5$;

(2) $\mathrm{O}$, styrene.

If the RI and UV are used simultaneously, the formation of cyclic oligomer of 14-CF-5 (sensitive to only RI detector) and the formation of cooligomer or copolymer (sensitive to both RI and UV detectors) can be detected in the same chromatogram. During the first stage, only the monomer 14-CF-5 reacted to form cyclic oligomers and there was no incorporation of styrene into the cyclic oligomers. Styrene was consumed only in the second stage and it was incorporated into a random copolymer with 14-CF-5. And the conversion of styrene seemed to reach some constant value when the comonomer 14-CF-5 reached equilibrium concentration. This is shown in Figures 5 and 6. This may be because the active species in the second stage are converted into oxonium ion through back-biting, once the system has reached equilibrium. The randomness of the copolymer was shown by gel chromatography and NMR after fractional reprecipitation of the polymer from benzene into methanol in order to remove the homopolystyrene, and into ether in order to remove the monomers and oligomers. Thus the active species in the second stage seems to be carbocationic. The fact that there are no
(1)

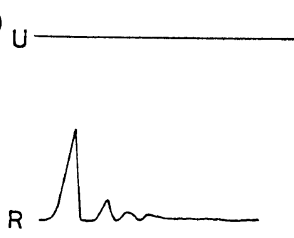

(2) $U$

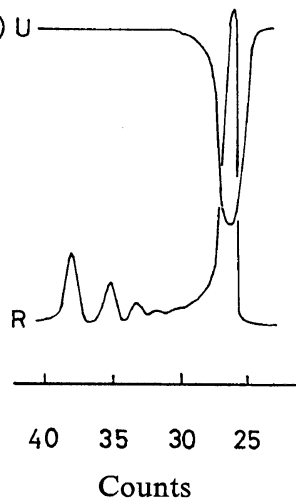

Figure 6. Change in gel chromatogram in the copolymerization of $14-\mathrm{CF}-5$ with styrene, at $0^{\circ} \mathrm{C}$ in dichloromethane: $[14-\mathrm{CF}-5]_{0}, 5.0 \times 10^{-1} M$; $[\mathrm{St}]$, $1.0 \mathrm{M} ;\left[\mathrm{BF}_{3} \mathrm{OEt}_{2}\right], 5.0 \times 10^{-3} M$; (1) $3 \mathrm{~min}$, conversion of [14-CF-5], 10.3\%, conv. of [St], $0.2 \%$;

(2) $10 \mathrm{~min}$, conversion of [14-CF-5], $40.0 \%$, conv. of [St], 9.0\%; U, detected by UV; R, detected by RI.

cooligomers formed during the first stage indicated that the active species in the first stage is different from that of the second stage.

Several mechanisms have been proposed for the cationic polymerization of 1,3-dioxa-cycloalkanes. ${ }^{1-4}$ Our observation of the formation of cyclic oligomers might support perhaps the Plesch's ring-expansion mechanism. ${ }^{3}$ However, direct observation of the carbocation has been reported. ${ }^{13}$ At the present, we can only speculate on the nature of the reactive species. In the polymerization of 14-CF-5, oxonium ion seems to be responsible for the slow propagation and fast back-biting during the first stage, and carbocation seems to be responsible for the fast propagation and copolymerization with styrene in the second stage. ${ }^{9}$

\section{REFERENCES}

1. (a) M. Okada, Y. Yamashita, and Y. Ishii, Makromol. Chem., 80, 196 (1964); (b) E. A. 
Bergman, E. B. Ludvig, V. A. Ponomarenko, and S. S. Medvedev, Vysokomol. Soedin. Ser. A, 11, 200 (1969).

2. (a) V. Jaacks and W. Kern, Makromol. Chem., 62, 1 (1963); (b) V. Jaacks, K. Boehlke, and E. Eberius, ibid., 118354 (1968).

3. P. H. Plesch and P. H. Westermann, J. Polym. Sci., Part C, 16, 3837 (1968).

4. (a) S. Penczek, Makromol. Chem., 134, 299 (1970); (b) S. Penczek, ibid., 175, 1217 (1974).

5. P. E. Black and D. J. Worsfold, J. Macromol. Sci.-Chem., A9, 1523 (1975).

6. Y. Kawakami and Y. Yamashita, J. Polym. Sci., Polym. Lett. Ed., 15, 213 (1977).

7. Y. Kawakami and Y. Yamashita, Polym. J., 9, 227 (1977).

8. Y. Kawakami and Y. Yamashita, Macromolecules, accepted for publication.

9. Y. Kawakami and Y. Yamashita, ibid., submitted for publication.

10. Y. Yamashita, M. Okada, and K. Suyama, Makromol. Chem., 111, 277 (1968).

11. Y. Yamashita, M. Okada, and H. Kasahara, ibid., 117, 256 (1968).

12. M. Okada, S. Kozawa, and Y. Yamashita, ibid., 127, 66 (1969).
13. Y. Yokoyama, M. Okada, and H. Sumitomo, ibid., 176, 795 (1976).

14. (a) D. J. Worsfold and A. M. Eastham, J. Am. Chem. Soc., 79, 897, 900 (1957); (b) R. J. Katnik and J. Schaefer, J. Org. Chem., 33, 384 (1968); (c) R. J. Kern, ibid., 33, 388 (1968); (d) J. Dale, Chem. Tech., 3 (1975).

15. J. B. Rose, J. Chem. Soc., 542 (1956).

16. J. Cooper and P. H. Plesch, ibid., Chem. Comm., 1017 (1974).

17. E. J. Goethals, Makromol. Chem., 175, 1309, 1513 (1974).

18. Y. Kawakami, T. Sugiura, and Y. Yamashita, to be published.

19. M. J. Astle, J. A. Zaslowsky, and P. G. Lafyatis, Ind. Eng. Chem., 46, 787 (1954).

20. J. W. Hill and W. H. Carothers, J. Am. Chem. Soc., 57, 925 (1935).

21. (a) P. J. Flory and J. A. Semlyen, J. Am. Chem. Soc., 88, 3209 (1966); (b) H. Jacobson and W. H. Stockmayer, J. Chem. Phys., 18, 1600 (1950).

22. Y. Yamashita and Y. Kawakami, ACS Polymer Preprints, 18, 35 (1977).

23. M. Okada, Y. Yamashita, and Y. Ishii, Makromol. Chem., 94, 181 (1966). 